\title{
Efeitos de Raça e Heterose na Composição Física da Carcaça e na Qualidade da Carne de Novilhos da Primeira Geração de Cruzamento entre Charolês e Nelore
}

\author{
Fabiano Nunes Vaz ${ }^{1}$, João Restle ${ }^{2}$, Ricardo Zambarda Vaz ${ }^{1}$, Ivan Luiz Brondani ${ }^{3}$, Régis \\ Augusto Carvalho Bernardes ${ }^{3}$, Cristian Faturi ${ }^{4}$
}

\begin{abstract}
RESUMO - Foram estudadas as características de carcaça de 463 novilhos, nascidos entre 1984 e 1996, gerados por dois sistemas de acasalamento: puros $(\mathrm{P})$ e cruzados $\mathrm{F}_{1}$. O sistema de acasalamento $\mathrm{P}$ foi constituído por 188 novilhos Charolês $(\mathrm{C})$ e $125 \mathrm{Nelore}(\mathrm{N})$ e o $F_{1}$, por 72 novilhos $1 / 2 \mathrm{C} 1 / 2 \mathrm{~N}$ e 78 1/2 N 1/2 C. Os animais cruzados foram superiores aos $\mathrm{P}$ em porcentagem de gordura na carcaça, relação músculo/osso, relação músculo + gordura/osso e marmoreio, sendo os níveis de heterose de 3,33; 2,92; 3,67; e 23,64\%, respectivamente. Na comparação entre sistemas de acasalamento, os animais $\mathrm{P}$ foram superiores aos $\mathrm{F}_{1}$ em porcentagem de músculo na carcaça, sendo a heterose de -3,08\%. Na comparação dentro do sistema de acasalamento dos P, os Charolês foram superiores aos Nelore em porcentagem de músculo $(68,4$ vs. $64,4 \%)$, relação músculo / osso $(3,57$ vs. 3,29$)$ e músculo + gordura/osso $(4,43$ vs. 4,30$)$, textura ( 3,80 vs. 3,58 pontos), maciez ( 6,81 vs. 4,89 pontos), palatabilidade ( 5,82 vs. 5,41 pontos) e suculência ( 6,28 vs. 5,66 pontos), enquanto os Nelore apresentaram maiores valores para porcentagem de gordura (19,6 vs. 16,3\%) e de osso na carcaça (19,7 vs. 19,2\%), força para corte das fibras $(9,29$ vs. $6,01 \mathrm{~kg})$ e quebras ao descongelamento ( 8,54 vs. 6,79\%) e cocção $(30,72$ vs. $28,12 \%)$. O cruzamento entre Charolês e Nelore propiciou heterose positiva e complementaridade genética aditiva para características de carcaça e da carne, importantes para os frigoríficos e os consumidores.
\end{abstract}

Palavras-chave: Bos indicus, Bos taurus, gordura de cobertura, maciez da carne, marmoreio, Shear

\section{Breed and Heterosis Effects on Carcass Physical Composition and Meat Quality of Steers from the First Generation of Crossbreeding Between Charolais and Nellore}

\begin{abstract}
Carcass characteristics of 463 steers, born during 1984 to 1996, from two breeding systems: straightbreds (S) and $\mathrm{F}_{1}$ crossbreds were studied. The $\mathrm{S}$ breeding system included the 188 Charolais $(\mathrm{C})$ and 125 Nellore $(\mathrm{N})$ steers and the $\mathrm{F}_{1}$ included $721 / 2 \mathrm{C} 1 / 2 \mathrm{~N}$ and $781 / 2 \mathrm{~N} 1 / 2 \mathrm{C}$ steers. $\mathrm{F}_{1}$ steers were superior than the purebreds in carcass fat percentage, muscle / bone relation, muscle + fat / bone relation and marbling score, being heterosis levels of 3.33, 2.92, 3.67, and 23.64\%, respectively. Comparing the two breeding systems, it was observed that the straightbred animals were superior than $\mathrm{F}_{1}$ in carcass muscle percentage, being the heterosis level of $-3.08 \%$. Within the $\mathrm{S}$ breeding system the Charolais showed higher carcass muscle percentage (68.4 vs. 64.4\%), muscle / bone relation (3.57 vs. 3.29$)$, muscle + fat / bone relation (4.43 vs. 4.30$)$, texture (3.80 vs. 3.58 points), tenderness (6.81 vs. 4.89 points), flavor (5.82 vs. 5.41 points) and juiciness ( 6.28 vs. 5.66 points), while the Nellore steers showed higher values for carcass fat percentage (19.6 vs. $16.3 \%)$, carcass bone percentage (19.7 vs. $19.2 \%)$, Shear force (9.29 vs. $6.01 \mathrm{~kg})$, thawing losses $(8.54$ vs. $6.79 \%)$ and cooking losses (30.72 vs. 28.12\%). The crossbreeding between Charolais and Nellore resulted in positive heterosis and additive genetic complementarily for carcass and meat characteristics important to the slaughterhouses and to the consumers.
\end{abstract}

Key Words: Bos indicus, Bos taurus, marbling, meat tenderness, Shear, subcutaneous fat

\section{Introdução}

No Brasil, em sua grande extensão territorial, notam-se dois sistemas bastante característicos de exploração pecuária. No sul do país, a exploração pecuária é baseada na produção e terminação de genótipos Bos taurus, onde destacam-se os rebanhos de raças que apresentam maior velocidade de cres- cimento, como a Charolês. Esses animais são terminados em campo nativo ou em pastagens anuais de estação fria. Já na região central do país, a predominância é da raça Nelore, a qual tem mostrado bom desempenho em pastagens perenes estivais.

Vários trabalhos têm demonstrado a importância dos cruzamentos para a pecuária de corte (Restle et al., 1995a,b,c; 2000; Roso, 1997; Perotto et al., 1998,

\footnotetext{
1Zootecnista, MS, Progepec Consultores Associados Ltda., Benjamin Constant, 930/313, Santa Maria-RS, CEP 97050-020. E.mail: fnvaz@terra.com.br

2Engenheiro Agrônomo, PhD, Professor Titular Departamento de Zootecnia - UFSM, Pesquisador do CNPq. E.mail: jorestle@ccr.ufsm.br

${ }^{3}$ Zootecnista, MS, Professor Assistente Departamento de Zootecnia - UFSM.

${ }^{4}$ Zootecnista, Aluno do curso de Pós-Graduação em Zootecnia - UFSM.
} 
2000; Restle \& Vaz, 1999), o qual tem sido considerado uma tecnologia que demanda baixos investimentos. $\mathrm{Na}$ América do Norte, vários trabalhos têm destacado bons resultados no cruzamento entre Nelore e raças de Bos taurus (Paschal et al., 1995; Wheeler et al., 1996, 1997; Franke, 1997).

O objetivo deste trabalho foi estudar o efeito do cruzamento das raças Charolês e Nelore e suas cruzas recíprocas, na primeira geração de cruzamento, assim como o efeito da heterozigose presente nos animais $F_{1}$ sobre a composição física da carcaça e as características qualitativas da carne de novilhos terminados aos dois anos de idade.

\section{Material e Métodos}

O presente experimento foi conduzido no Setor de Bovinocultura de Corte e no Laboratório de Carnes do Departamento de Zootecnia da Universidade Federal de Santa Maria - RS (UFSM).

Os dados analisados referem-se a 188 novilhos Charolês (C), 125 novilhos Nelore (N), 72 novilhos $1 / 2 \mathrm{C} 1 / 2 \mathrm{~N}$ e 78 novilhos $1 / 2 \mathrm{~N} \mathrm{1/2} \mathrm{C}$, nascidos no período de 1984 a 1996, totalizando 463 animais. Por ocasião do início do projeto, em 1984, foram utilizadas fêmeas Charolês e Nelore aptas à reprodução, oriundas de diferentes rebanhos da região. Essas fêmeas foram divididas aleatoriamente em dois grupos e geraram produtos puros e cruzados $\left(\mathrm{F}_{1}\right)$.

O sêmen de seis touros de cada raça (Charolês e Nelore) foi utilizado a cada ano, sendo que esse sêmen foi adquirido junto às casas comerciais especializadas, procurando-se sempre touros de qualidade média dentro da sua raça. O sêmen de cada touro foi utilizado por no mínimo dois anos consecutivos. Por ocasião da inseminação artificial, após a identificação da raça, que deveria ser utilizada em determinado ventre, a escolha do sêmen foi aleatória.

Quatro touros de cada raça foram utilizados para o repasse em monta a campo. Os touros escolhidos foram, também, de qualidade média, trazidos de cabanhas tradicionais que se dispuseram a ceder seus reprodutores para a instituição. Os touros Charolês que geraram os novilhos Charolês foram os mesmos que geraram produtos $1 / 2 \mathrm{C} 1 / 2 \mathrm{~N}$, assim como os touros Nelore que geraram novilhos Nelore foram os mesmos que produziram novilhos $1 / 2 \mathrm{~N} 1 / 2 \mathrm{C}$. Constam na Tabela 1 o número de animais por grupo racial e o número de pais utilizados a cada ano.
Tabela 1 - Número de animais e de touros utilizados a cada ano

Table 1 - Number of animals and sires used each year

\begin{tabular}{|c|c|c|c|c|c|c|}
\hline \multicolumn{2}{|c|}{$\begin{array}{l}\text { Ano de } \\
\text { nascimento } \\
\text { Year of birth }\end{array}$} & \multicolumn{3}{|c|}{$\begin{array}{l}\text { Composição } \\
\text { racial do novilho } \\
\text { Steer breed } \\
\text { composition }\end{array}$} & \multicolumn{2}{|c|}{$\begin{array}{l}\text { Raça do } \\
\text { touro } \\
\text { Sire } \\
\text { breed }\end{array}$} \\
\hline & $\mathrm{C}$ & $\mathrm{N}$ & $1 / 2 \mathrm{C} 1 / 2 \mathrm{~N}$ & $1 / 2 \mathrm{~N} 1 / 2 \mathrm{C}$ & $\mathrm{C}$ & $\mathrm{N}$ \\
\hline 1984 & 5 & - & - & - & $10^{*}$ & 10 \\
\hline 1985 & 8 & 12 & 4 & 7 & 10 & 10 \\
\hline 1986 & 13 & 5 & 13 & 8 & 10 & 10 \\
\hline 1987 & 12 & 10 & 8 & 9 & 10 & 10 \\
\hline 1988 & 5 & 13 & 1 & 10 & 10 & 10 \\
\hline 1989 & 21 & 13 & 14 & 13 & 10 & 10 \\
\hline 1990 & 18 & 13 & 7 & 11 & 10 & 10 \\
\hline 1991 & 21 & 14 & 4 & 3 & 10 & 10 \\
\hline 1992 & 15 & 11 & 10 & 7 & 10 & 10 \\
\hline 1993 & 17 & 6 & 6 & 7 & 10 & 10 \\
\hline 1994 & 13 & 12 & 2 & 2 & 10 & 10 \\
\hline 1995 & 22 & 10 & 3 & 1 & 10 & 10 \\
\hline 1996 & 18 & 6 & - & - & 10 & 10 \\
\hline Total & 188 & 125 & 72 & 78 & & \\
\hline
\end{tabular}

* A cada ano foram utilizados, para cada raça, seis touros para a inseminação artificial e quatro touros para repasse em monta natural a campo.

* Each year, the semen of six bulls for artificial insemination and four clean up bulls were used for each breed.

Os animais foram desmamados e castrados aos sete meses de idade. A cada ano, o manejo durante a recria era o mesmo para todos os grupos genéticos. No segundo inverno, os animais nascidos durante a mesma época de parição, e até aquele momento recriados sob as mesmas condições, podiam ser divididos em dois grupos, tendo-se o cuidado para que cada grupo possuísse animais de todas as composições raciais. Essa divisão era feita quando se determinava o sistema de alimentação que não comportava todo o lote de animais, portanto, cada grupo contemporâneo possuía animais de todas as composições raciais disponíveis e era formado por animais recriados e terminados rigorosamente sob as mesmas condições. A terminação dos novilhos variou de ano para ano, podendo ter sido em confinamento ou em pastagem cultivada de inverno, com a utilização ou não de suplemento energético.

Aos dois anos de idade, quando todos os animais do mesmo grupo contemporâneo estavam terminados, os mesmos eram vendidos para frigoríficos comerciais, onde foi realizado o estudo das carcaças. Após o abate, a carcaça do animal foi identificada antes de entrar para a câmara de resfriamento. 
Depois de resfriar as carcaças por 24 horas a $2^{\circ} \mathrm{C}$, foram realizadas as avaliações subjetivas de marmoreio, cor e textura da carne. O músculo Longissimus dorsi foi seccionado na altura da $12^{\mathrm{a}}$ costela, conforme metodologia sugerida por Muller (1987). Para determinar as porcentagens de músculo, gordura e osso, seguiu-se a metodologia descrita por Hankins \& Howe (1946). Para a realização das avaliações da carne em laboratório, utilizou-se a porção do músculo Longissimus dorsi extraída da amostra utilizada para determinação da composição física da carcaça. Após a dissecação, a porção do músculo Longissimus foi embalada, identificada e congelada.

Do músculo congelado, foram extraídas duas fatias de 2,5 cm de espessura, obtidas perpendicularmente ao comprimento do músculo, as quais foram utilizadas para avaliação da quebra ao descongelamento, quebra à cocção e resistência das fibras ao corte (fatia B) e avaliação das características sensoriais (fatia $A$ ).

Para cálculo das perdas ao descongelamento e à cocção, foi realizada a pesagem da fatia $B$, ainda congelada, depois de descongelada (antes de ser levada ao forno) e após o cozimento, que aconteceu até que a temperatura interna da fatia atingisse $70^{\circ} \mathrm{C}$. A pesagem após o cozimento foi realizada após a fatia voltar à temperatura ambiente.

Após o cozimento e a pesagem da fatia, foram extraídas três amostras de feixes de fibras, circulares, com $1 \mathrm{~cm}^{2}$ de área, as quais foram cortadas perpendicularmente à fibra, por intermédio do aparelho Warner-Bratzler Shear. Para obter-se a medida, calculou-se a média aritmética de seis leituras (duas por amostra).

As características sensoriais da carne foram avaliadas após a cocção das fatias de músculo, onde foi distribuída uma porção de $1 \mathrm{~cm}^{3}$ para cada um dos avaliadores, os quais são previamente treinados para atribuir valores de 1 a 9 para as características maciez, suculência e palatabilidade da carne. Para as três características, os valores aumentam conforme melhoram os atributos da carne, ou seja, mais macia, saborosa ou suculenta.

O delineamento experimental utilizado foi o inteiramente casualizado, com número diferente de repetições por tratamento. Definiu-se uma variável chamada SA (sistema de acasalamento) para a análise estatística. As duas classes desta variável foram definidas como: $S A$ definidos, que abrange os animais das raças definidas Charolês e Nelore; e $S A F_{1}$, que abrange animais cruzados da geração 1 , ou seja, animais $1 / 2 \mathrm{C} 1 / 2 \mathrm{~N}$ e $1 / 2 \mathrm{~N} 1 / 2 \mathrm{C}$, sendo que a primeira raça representa a raça do pai.

Todas as características de interesse apresentaram distribuição normal e foram analisadas pelo procedimento "PROC GLM", do software SAS (1990), utilizando-se o seguinte modelo estatístico:

$$
\begin{gathered}
\mathrm{Y}_{\mathrm{ijklm}}=\mu+\mathrm{GC}_{\mathrm{i}}+\mathrm{IV}_{\mathrm{j}}+\mathrm{SA}_{\mathrm{k}}+\mathrm{R}_{\mathrm{lik}}+\mathrm{b} \\
\left(\mathrm{IA}_{\mathrm{ijklm}}-\mathrm{I}\right)+\mathrm{e}_{\mathrm{ijklm}}
\end{gathered}
$$

em que: $Y_{i j k l m}$ representa a observação realizada no n-ésimo animal, pertencente ao i-ésimo grupo contemporâneo, ao k-ésimo sistema de acasalamento e à 1-ésima composição racial, e cuja mãe ao parto pertence a j-ésima classe de idade; $\mu$, a média geral da característica; $\mathrm{GC}_{\mathrm{i}}$, o efeito do i-ésimo grupo contemporâneo $(i=1, \ldots, 25) ; \mathrm{IV}_{\mathrm{j}}$, o efeito da $\mathrm{j}$-ésima classe idade da vaca $(\mathrm{j}=3, \ldots, 15) ; \mathrm{SA}_{1}$, o efeito do k-ésimo sistema de acasalamento $(\mathrm{k}=1,2) ; \mathrm{R}_{\mathrm{l}: \mathrm{k}}, \mathrm{o}$ efeito da 1-ésima composição racial, dentro do k-ésimo sistema de acasalamento $(1=1,2)$; b, coeficiente de regressão linear da característica, em função da idade do animal; IA $_{\text {ijklm, }}$, a idade em dias ao abate do m-ésimo animal; I, média da idade dos animais; $\mathrm{e}_{\mathrm{ijklm}}$, o efeito residual, associado à observação realizada no $\mathrm{m}$-ésimo animal, $\sim \operatorname{NID}\left(0, \sigma^{2} \mathrm{e}\right)$.

Nas análises preliminares, testou-se o efeito quadrático da IA e o efeito do peso do animal aos 12 meses. Como esses efeitos não foram significativos, eles foram removidos do modelo estatístico final. A classe idade da vaca foi incluída no modelo matemático em função das diferenças que podem ocorrer no desenvolvimento pré-desmame dos animais, pelas variações na produção de leite de vacas de diferentes idades. As classes de idade da vaca ao parto variaram de três a quinze anos.

Para as comparações entre SA, foi utilizado o teste F. As médias para cada característica extraídas da comparação entre os SA (puros e cruzados $\mathrm{F}_{1}$ ) foram utilizadas para calcular a heterose, por intermédio da seguinte fórmula:

Heterose $=\left[\mathrm{MF}_{1}-\mathrm{MP}\right] \mathrm{X} 100 / \mathrm{MP}$, em que $\mathrm{MF}_{1}$ representa a média ajustada dos animais cruzados $\mathrm{F}_{1}$ e MP, a média ajustada dos animais puros.

A comparação entre SA contrasta as médias dos animais puros versus a média dos animais $\mathrm{F}_{1}$. Já as comparações das composições raciais foram realizadas dentro dos $\mathrm{SA}\left(\mathrm{R}_{1: \mathrm{k}}\right.$, no modelo estatístico). Os seguintes contrastes foram estudados:

Charolês versus Nelore: permite uma estimativa da diferença aditiva entre as raças Charolês e Nelore. 
1/2 C 1/2 N versus 1/2 N 1/2 C: estima o efeito recíproco das raças, decorrente principalmente de possível efeito materno.

\section{Resultados e Discussão}

$\mathrm{Na}$ Tabela 2 são apresentados os resultados resumidos da análise de variância para as características dependentes estudadas.

Na Tabela 3, são apresentadas as médias ajustadas referentes à composição física da carcaça dos novilhos, assim como as médias ajustadas de cada sistema de acasalamento (SA) e a heterose medida na $F_{1}$.

$\mathrm{Na}$ comparação entre os SA, observa-se que as médias estimadas para composição da carcaça mostram maior porcentagem de gordura nos cruzados, sendo a heterose de 3,33\%. Em seus trabalhos, Slanger et al. (1985) e Urick et al. (1989) comentam que as características relacionadas à deposição de gordura na carcaça são as que apresentam maiores valores de heterose. Usando animais Bos taurus, Gregory et al. (1994) estimaram a heterose retida na terceira geração $\left(\mathrm{F}_{3}\right)$ de populações compostas, concluindo que esta só foi significativa para porcentagem de gordura na carcaça, salientando a grande variabilidade que esta característica apresenta nas diferentes raças. Segundo Koger (1980), as características que apresentam maior variabilidade entre as raças envolvidas no cruzamento são as que resultam em maiores valores de heterose.

A heterose foi negativa para porcentagem de osso na carcaça, o que acarretou que os animais cruzados apresentassem maiores relações músculo/ osso e músculo + gordura/osso, sendo as heteroses de 2,92 e 3,67\%, respectivamente. Esses resultados mostram que o cruzamento traz vantagens para essas características, de grande importância para frigoríficos e consumidores.

Já na comparação dentro dos SA, verifica-se na Tabela 3 que a porcentagem de músculo dos Charolês foi superior aos Nelore $(\mathrm{P}<0,05)$, os quais apresentaram maior porcentagem de gordura do que os primeiros. Resultados semelhantes foram citados por Moletta $\&$ Restle (1996a). Barber et al. (1981) estudaram o comportamento da raça Charolês com respeito a sua deposição de gordura em comparação aos novilhos de uma raça considerada mais precoce em acabamento (Aberdeen Angus), não verificando diferença na espessura de gordura sobre a carcaça, quando se permitiu que o Charolês atingisse o seu peso adulto.
Ainda na Tabela 3, observa-se que as relações músculo/osso e músculo + gordura/osso foram maiores $(\mathrm{P}<0,05)$ nos novilhos Charolês que nos Nelore. Luchiari Filho et al. (1989) não verificaram diferença no percentual de porção comestível entre animais Nelore e Canchim x Nelore. Comparando vacas de descarte Charolês ou Nelore, Perobelli et al. (1995) não observaram diferença na relação músculo / osso das carcaças. Ao estudarem novilhos Nelore em comparação com Simental x Nelore, Feijó et al. (1997) também verificaram que não houve diferença significativa entre os dois genótipos na porção comestível da carcaça.

Na comparação entre os novilhos $\mathrm{F}_{1}$, observa-se maior porcentagem de gordura nos animais $1 / 2 \mathrm{C} 1 / 2 \mathrm{~N}$ em relação aos $1 / 2 \mathrm{~N} \mathrm{1/2} \mathrm{C} \mathrm{(Tabela} \mathrm{3).} \mathrm{Os} \mathrm{animais}$ $1 / 2 \mathrm{C} 1 / 2 \mathrm{~N}$ também foram superiores na quantidade de marmoreio da carne, conforme pode ser observado na Tabela 4.

Observa-se na Tabela 4 diferença $(\mathrm{P}<0,05)$ de $28 \%$ no marmoreio da carne dos dois grupos de novilhos $\mathrm{F}_{1}$, diferença bastante alta, se for considerado que os dois genótipos possuem a mesma composição genética. Analisando o cruzamento dialélico entre duas raças, Marshall et al. (1987) verificaram que o grau de marmoreio foi de 5,04 pontos em animais $1 / 2$ Aberdeen Angus 1/2 Pardo Suíço e 4,06 pontos em animais 1/2 Pardo Suíço 1/2 Aberdeen Angus. Segundo Marshall et al. (1987), essa diferença pode ser atribuída ao maior desenvolvimento dos terneiros amamentados por vacas de genótipos com melhor produção leiteira, resultando em acúmulo de gordura intramuscular durante o período que o animal recebe alto aporte energético; esse efeito seria refletido mais tarde na carcaça do animal, o que é suportado por Paschal et al. (1995).

Já Olson et al. (1978) afirmam que o ganho compensatório na fase pós-desmame elimina as diferenças existentes na fase de aleitamento, fazendo com que as características de peso e desenvolvimento da carcaça não difiram entre si em animais abatidos até os dezessete meses. Também os trabalhos que estudaram os efeitos da heterose materna não constataram influência desse efeito sobre as características de carcaça dos novilhos (Olson et al., 1978; Gregory et al., 1987; Arthur et al., 1989; Marshall et al., 1990; DeRouen et al., 1992a,b; Johnston et al., 1992).

Buscando explicar as diferenças nas características pré-desmame entre cruzas recíprocas observadas em algumas populações, Rohrer et al. (1994) 


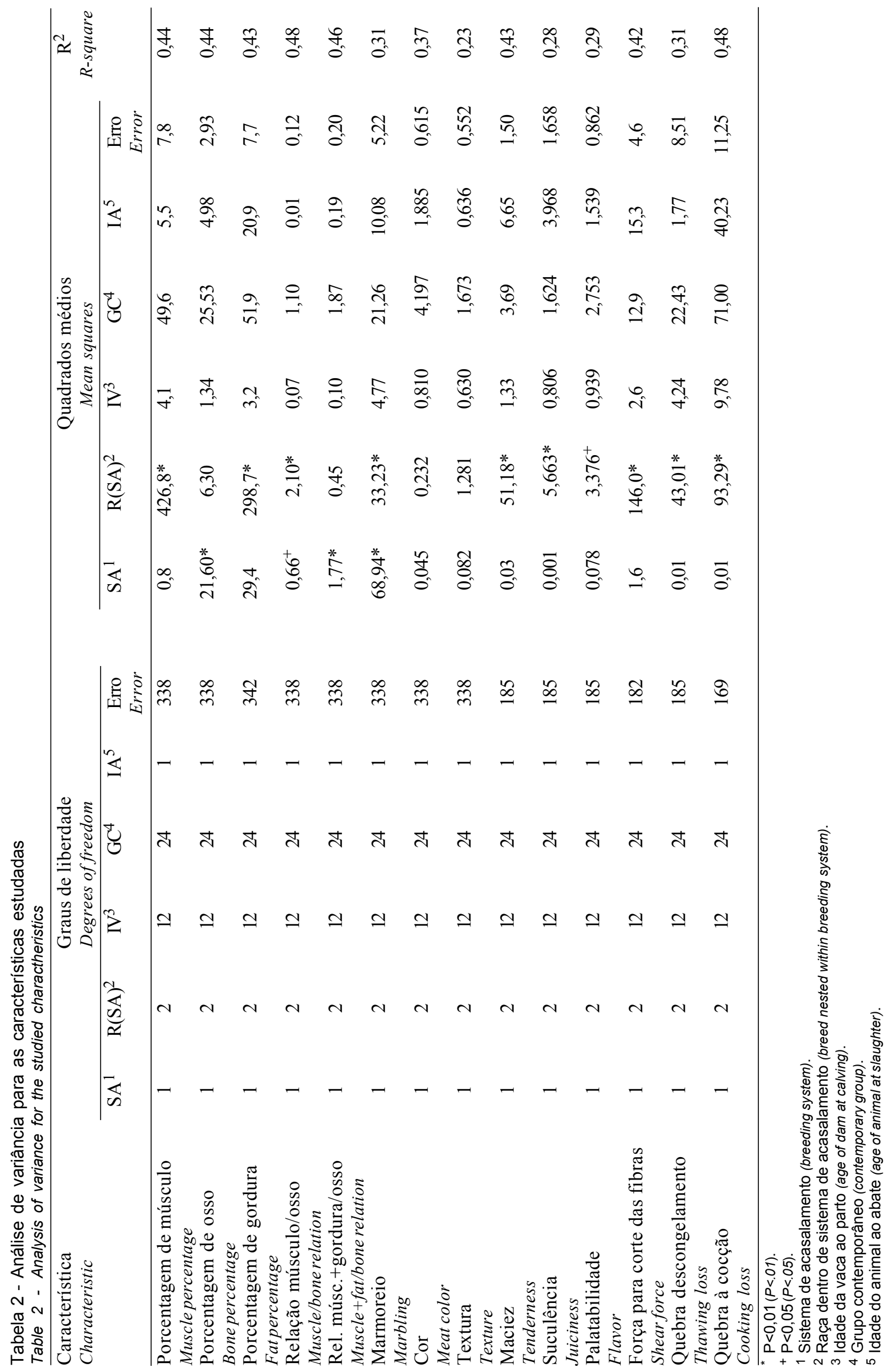


Tabela 3 - Valores médios para composição física da carcaça de novilhos com relação à composição racial Table 3 - Values for carcass physical composition according to the breed composition

\begin{tabular}{lccccc}
\hline $\begin{array}{l}\text { Composição racial } \\
\text { Breed composition }\end{array}$ & $\begin{array}{c}\text { Músculo, } \% \\
\text { Muscle, } \%\end{array}$ & $\begin{array}{c}\text { Osso, } \% \\
\text { Bone, } \%\end{array}$ & $\begin{array}{c}\text { Gordura, } \% \\
\text { Fat, } \%\end{array}$ & $\begin{array}{c}\text { Músculo/osso } \\
\text { Muscle /bone }\end{array}$ & $\begin{array}{c}\text { Musc.+gord/osso } \\
\text { Muscle+fat/bone }\end{array}$ \\
\hline Charolês (C) & $68,4^{\mathrm{a} 2}$ & $19,2^{\mathrm{b}}$ & $16,3^{\mathrm{b}}$ & $3,57^{\mathrm{a}}$ & $4,43^{\mathrm{a}}$ \\
Nelore(N) & $64,4^{\mathrm{b}}$ & $19,7^{\mathrm{a}}$ & $19,6 \mathrm{a}$ & $3,29^{\mathrm{b}}$ & $4,30^{\mathrm{b}}$ \\
Média puros & $66,4^{\mathrm{A}}$ & $19,5^{\mathrm{B} 1}$ & $18,0^{\mathrm{B}}$ & $3,43^{\mathrm{B}}$ & $4,36^{\mathrm{B}}$ \\
Straightbreds mean & & & & & \\
$1 / 2 \mathrm{C} 1 / 2 \mathrm{~N}$ & $65,7^{\mathrm{d} 3}$ & $19,0^{\mathrm{c}}$ & $19,1^{\mathrm{c}}$ & $3,51^{\mathrm{c}}$ & $4,53^{\mathrm{c}}$ \\
$1 / 2 \mathrm{~N} 1 / 2 \mathrm{C}$ & $66,8^{\mathrm{c}}$ & $18,9^{\mathrm{c}}$ & $18,1^{\mathrm{d}}$ & $3,55^{\mathrm{c}}$ & $4,52^{\mathrm{c}}$ \\
Média F & $66,3^{\mathrm{A}}$ & $18,9^{\mathrm{A}}$ & $18,6^{\mathrm{A}}$ & $3,53^{\mathrm{A}}$ & $4,52^{\mathrm{A}}$ \\
$F_{1}$ mean & & & & $2,92(\mathrm{~S})$ & $3,67(\mathrm{~S})$ \\
Heterose, $\%$ & $-0,15\left(\mathrm{NS}^{4}\right)$ & $-3,08(\mathrm{~S})$ & $3,33(\mathrm{~S})$ & & \\
Heterosis, $\%$ & & & &
\end{tabular}

${ }^{1} \mathrm{~A}, \mathrm{~B}$, na coluna, na comparação entre puros e $F_{1}$ diferem pelo teste " $\mathrm{t}$ " $(\mathrm{P}<0,05)\left(A, B\right.$, in the column, for comparison between straigthbreds and $F_{1}$, differ by " $t$ " test $[P<.05])$.

2 a,b, na coluna, na comparação entre Charolês e Nelore, diferem pelo teste " $\mathrm{t}$ " $(\mathrm{P}<0,05)(a, b$, in the column, for comparison between Charolais and Nellore, differ by "t" test $[P<.05])$.

${ }^{3} \mathrm{C}$, d, na coluna, na comparação entre $1 / 2 \mathrm{C} 1 / 2 \mathrm{~N}$ e $1 / 2 \mathrm{~N} 1 / 2 \mathrm{C}$, diferem pelo teste "t" $(\mathrm{P}<0,05)(c, d$, in the colunn, for comparison between $1 / 2 \mathrm{C} 1 / 2 \mathrm{~N}$ and 1/2 N 1/2 C, differ by "t" test [P<.05]).

4 indica heterose significativa (S) ou não-significativa (NS) $(P>0,05)$ (Indicate significant (S) or not significant heterosis [NS] [P>.05]).

estimaram valores da herança citoplasmática sobre as características peso ao nascer, peso ao desmame e ganho de peso pós-desmame em animais Brangus, verificando pequena variação fenotípica (média de $0,002 \%$ ) explicada por este efeito. Também em seu trabalho, Alencar et al. (1997) verificaram que, em animais Canchim, o efeito da herança citoplasmática não explicou as variações fenotípicas dos animais, pois apresentou níveis bastante baixos nas características peso ao nascer $(0,45 \%)$, peso ao desmame $(0,59 \%)$ e peso aos doze meses $(0,00 \%)$.

Na comparação entre os animais puros, observa-se que o marmoreio não diferiu entre os dois genótipos avaliados. DeRouen et al. (1992b) compararam as cruzas entre Charolês, Brahman, Aberdeen Angus e Hereford, verificando que, no cruzamento entre duas ou três raças, os genótipos que apresentaram Charolês em sua composição produziram carcaças com menores graus de marmoreio. Nos animais puros, o grau de marmoreio foi de 3,9 e 3,2 pontos, respectivamente, para Charolês e Brahman.

Comparando vacas de descarte Charolês e Nelore, Perobelli et al. (1994) verificaram maior marmoreio na carne de vacas Nelore. Wheeler et al. (1997) fixaram o grau de marmoreio como ponto de abate, verificando que, entre doze raças de reprodutores, os filhos de Charolês e os filhos de Nelore foram os que mostraram carcaças mais pesadas.

$\mathrm{Na}$ Tabela 4, pode-se observar ainda que os animais puros não diferiram na cor da carne. Con- trastando animais Hereford e Brahman, Wheeler et al. (1990) não observaram diferença na coloração da carne. Já ao estudarem as características de carcaça de animais abatidos aos quatorze meses, dos genótipos 3/4 C 1/4 N ou 3/4 Hereford 1/4 N, Rocha et al. (1997) verificaram que os cruza Charolês apresentaram carne mais clara que os cruza Hereford.

Com relação à textura da carne (Tabela 4), observa-se que esta foi mais fina $(\mathrm{P}<0,05)$ nos animais $\mathrm{C}$. Trabalhando com animais Brahman, Crouse et al. (1989) verificaram que a textura da carne piorou, à medida que aumentou a proporção de Bos indicus, obtendo valores de 5,82; 5,68; e 5,30 pontos, respectivamente para animais $1 / 4,1 / 2$ e $3 / 4$ Brahman. Também Wheeler et al. (1990) verificaram uma textura significativamente mais fina na carcaça de animais Hereford em comparação com Brahman. Por outro lado, Feijó et al. (1997), ao compararem animais Nelore e $\mathrm{F}_{1}$ Simental $\mathrm{x}$ Nelore, abatidos com mesmo grau de acabamento (8 $\mathrm{mm}$ ), e Restle et al. (1999), quando avaliaram diferentes genótipos de Nelore x Hereford, abatidos aos 24 meses, não observaram que o Nelore tenha prejudicado a textura da carne.

$\mathrm{Na}$ comparação entre os SA das características apresentadas na Tabela 4, observa-se que somente o marmoreio apresentou heterose significativa $(23,64 \%$; $\mathrm{P}<0,05)$. Heterose alta para marmoreio da carne foi verificada por Marshall et al. (1987), ao analisarem os efeitos genéticos sobre o desenvolvimento e as características de carcaça dos novilhos Aberdeen 
Tabela 4 - Valores para marmoreio, cor e textura da carne com relação à composição racial Table 4 - Values for marbling, meat color and texture, according to the breed composition

\begin{tabular}{|c|c|c|c|}
\hline $\begin{array}{l}\text { Composição racial } \\
\text { Breed composition }\end{array}$ & $\begin{array}{l}\text { Marmoreio, pontos } \\
\text { Marbling, score }^{1}\end{array}$ & $\begin{array}{c}\text { Cor, pontos }{ }^{2} \\
\text { Meat color, score }\end{array}$ & $\begin{array}{l}\text { Textura, pontos } \\
\text { Texture, score } \\
\text { Ter }\end{array}$ \\
\hline Charolês (C) & $4,52^{\mathrm{a}}$ & $3,57^{\mathrm{a}}$ & $3,80^{\mathrm{a} 5}$ \\
\hline Nelore (N) & $3,93^{\mathrm{a}}$ & $3,56^{\mathrm{a}}$ & $3,58 \mathrm{~b}$ \\
\hline \multicolumn{4}{|l|}{ Média puros } \\
\hline Straightbreds mean & $4,23^{\mathrm{B} 4}$ & $3,57^{\mathrm{A}}$ & $3,69^{\mathrm{A}}$ \\
\hline $1 / 2 \mathrm{C} 1 / 2 \mathrm{~N}$ & $5,87^{\mathrm{c} 6}$ & $3,53^{\mathrm{c}}$ & $3,69^{\mathrm{c}}$ \\
\hline $1 / 2 \mathrm{~N} 1 / 2 \mathrm{C}$ & $4,59^{d}$ & $3,66^{\mathrm{c}}$ & $3,62^{\mathrm{c}}$ \\
\hline Média $F_{1}$ & $5,23^{\mathrm{A}}$ & $3,59^{\mathrm{A}}$ & $3,65^{\mathrm{A}}$ \\
\hline \multicolumn{4}{|l|}{$F_{1}$ mean } \\
\hline Heterose, $\%$ & $23,64\left(S^{7}\right)$ & $0,56(\mathrm{NS})$ & $-1,08(\mathrm{NS})$ \\
\hline Heterosis, \% & & & \\
\hline
\end{tabular}

${ }^{1}$ Escala de 1 a 18 pontos, sendo $3=$ traços,$+ 4=$ leve menos, $5=$ leve e $6=$ leve mais [score from 1 to 18 points, being $3=$ traces,$+ 4=$ slight minus, $5=$ slight and $6=$ slight plus].

2Escala de 1 a 5 pontos, sendo $3=$ vermelha levemente escura e $4=$ vermelha [score from 1 to 5 points, being $3=$ slight dark red and $4=$ red].

${ }^{3}$ Escala de 1 a 5 pontos, sendo $3=$ levemente grosseira e $4=$ fina [score from 1 to 5 points, being $3=$ slightly coarse and $4=$ fine].

${ }^{4} \mathrm{~A}, \mathrm{~B}$, na coluna, na comparação entre puros e $\mathrm{F}_{1}$ diferem pelo teste " $\mathrm{t}$ " $(\mathrm{P}<0,05)\left[A, B\right.$, in the column, for comparision between straigthbreds and $F_{1}$, differ by "t" test $(P<.05)]$.

$5 \mathrm{a}, \mathrm{b}$, na coluna, na comparação entre Charolês e Nelore, diferem pelo teste " $\mathrm{t}$ " $(\mathrm{P}<0,05)[a, b$, in the column, for comparison between Charolais and Nellore, differ by "t" test $(P<.05)]$.

${ }^{6} \mathrm{c}, \mathrm{d}$, na coluna, na comparação entre $1 / 2 \mathrm{C} 1 / 2 \mathrm{~N} \mathrm{e} 1 / 2 \mathrm{~N} 1 / 2 \mathrm{C}$, diferem pelo teste " $\mathrm{t}$ " $(\mathrm{P}<0,05)[c, d$, in the colunn, for comparison between $1 / 2 \mathrm{C} 1 / 2 \mathrm{~N}$ and $1 / 2 N 1 / 2 C$, differ by " $t$ " test $(P<.05)]$.

7 Indica heterose significativa (S) ou não-significativa (NS) $(P>0,05)$ [indicate significant (S) or not significant heterosis $(N S)(P>.05)$ ].

Angus e Pardo Suíço, observando que o efeito do vigor híbrido individual para marmoreio atingiu um nível de heterose de $24,9 \%$. O alto valor da heterose observado para uma característica que reflete o acúmulo de gordura corporal também é relatado por Slanger et al. (1985) e Urick et al. (1989).

$\mathrm{Na}$ Tabela 5, são apresentados os resultados referentes às características sensoriais da carne e à força necessária para cortar as fibras da carne.

$\mathrm{Na}$ Tabela 5, verifica-se que a heterose não foi significativa para nenhuma das características sensoriais, assim como para os valores de Shear. Ao analisarem o cruzamento entre Pardo Suíço e Aberdeen Angus, Marshall et al. (1987) verificaram que os animais cruzados apresentaram carne mais dura, sendo a heterose de $2 \%$ para resistência das fibras ao corte.

Ao estimarem os efeitos heteróticos retidos nas três primeiras gerações de populações compostas, Gregory et al. (1994) concluíram que a heterose retida na terceira geração foi significativa para maciez da carne e palatabilidade, sendo de $0,44 \mathrm{~kg}$ para resistência das fibras ao corte e $-0,24$ pontos para maciez medida pelo painel. Na segunda geração, a heterose retida de 0,08 pontos para palatabilidade da carne também foi significativa. Os mesmos autores observaram, em seu trabalho, que existem grandes diferenças entre raças e dentro de uma mesma raça para características sensoriais da carne.

Analisando-se os genótipos dentro do SA, observa-se que, tanto mecanicamente como pelo painel de degustadores, o Charolês apresentou uma carne mais macia que o Nelore. DeRouen et al. (1992b), ao estudarem a maciez da carne medida mecanicamente, verificaram que a força necessária para romper as fibras da carne de novilhos Charolês foi de 9,5 $\mathrm{kg}$ e dos Brahman, de 13,2 kg. No mesmo trabalho, os autores relataram benefícios no cruzamento da raça Brahman com as raças Bos taurus sobre a qualidade da carcaça, mas, apesar de o efeito heterótico dessa raça ser positivo para maciez da carne, a sua inclusão em cruzamentos pode diminuir a maciez da carne, devido ao seu forte efeito genético aditivo. Por outro lado, ao estudarem animais cruzados de diferentes genótipos, Wheeler et al. (1996) relataram que, embora os cruzas Nelore tenham apresentado menores valores para maciez da carne, a magnitude da diferença foi de pouca importância prática. Moletta \& Restle (1996b) verificaram a força necessária para romper as fibras da carne de novilhos Charolês e Nelore, verificando valores de 8,14 e 10,2 kg, respectivamente.

Já ao comentar a inclusão de zebuínos em cruzamentos sobre a maciez da carne, Dikeman (1995), citado por O'Connor et al. (1997), alerta que, pelo 
Tabela 5 - Valores para características sensoriais e força para corte das fibras (FCF) da carne com relação à composição racial Table 5 - Values for sensorial characteristics and Shear force, according to the breed composition

\begin{tabular}{|c|c|c|c|c|}
\hline $\begin{array}{l}\text { Composição racial } \\
\text { Breed composition }\end{array}$ & $\begin{array}{c}\text { Maciez, } \\
\text { pontos }^{1} \\
\text { Tenderness, } \text { score }^{1}\end{array}$ & $\begin{array}{c}\text { Suculência, } \\
\text { pontos }{ }^{1} \\
\text { Juiciness, score }{ }^{1}\end{array}$ & $\begin{array}{l}\text { Palatabilidade, } \\
\text { pontos }{ }^{1} \\
\text { Flavor, score } 1 \\
\end{array}$ & $\begin{array}{c}\mathrm{FCF}, \mathrm{kg} \\
\text { Shear force, } \\
\mathrm{kg}\end{array}$ \\
\hline Charolês (C) & $6,81^{\mathrm{a} 2}$ & $6,28^{a}$ & $5,82^{\mathrm{a}}$ & $6,01^{\mathrm{a}}$ \\
\hline Nelore (N) & $4,89^{\mathrm{b}}$ & $5,66^{\mathrm{b}}$ & $5,41^{\mathrm{b}}$ & $9,29^{b}$ \\
\hline $\begin{array}{l}\text { Média puros } \\
\text { Straightbreds mean }\end{array}$ & $5,85^{\mathrm{A}}$ & $5,97^{\mathrm{A}}$ & $5,61^{\mathrm{A}}$ & $7,65^{\mathrm{A}}$ \\
\hline $1 / 2 \mathrm{C} 1 / 2 \mathrm{~N}$ & $5,90^{\mathrm{c}}$ & $6,06^{\mathrm{c}}$ & $5,84^{\mathrm{c}}$ & $7,85^{\mathrm{c}}$ \\
\hline $1 / 2 \mathrm{~N} 1 / 2 \mathrm{C}$ & $5,86^{\mathrm{c}}$ & $5,88^{\mathrm{c}}$ & $5,48^{\mathrm{c}}$ & $7,89^{\mathrm{c}}$ \\
\hline Média $F_{1}$ & $5,88^{\mathrm{A}}$ & $5,97^{\mathrm{A}}$ & $5,66^{A}$ & $7,87^{\mathrm{A}}$ \\
\hline $\begin{array}{l}F_{1} \text { mean } \\
\text { Heterose, \% } \\
\text { Heterosis, \% }\end{array}$ & $0,51\left(\mathrm{NS}^{3}\right)$ & $0,03(\mathrm{NS})$ & $0,89(\mathrm{NS})$ & $2,88(\mathrm{NS})$ \\
\hline $\begin{array}{l}1 \text { escala de } 1 \text { a } 9 \text { pontos } \\
\text { extremamente saboros } \\
2 \text { a,b, na coluna, na comp } \\
\text { differ by "t test" ( } P<.05)] \text {. } \\
3 \text { Indica heterose não-si }\end{array}$ & $\begin{array}{l}1=\text { extremamente du } \\
\text { from } 1 \text { to } 9 \text { points, being } \\
\text { entre Charolês e Nelor } \\
\text { va }(P>0,05) \text { rindicate no }\end{array}$ & $\begin{array}{l}\text { suculência e sem sa } \\
\text { mly tough, dry, undesira } \\
\text { n pelo "Teste t" }(P<0, \\
\text { int heterosis }(P>.05)] \text {. }\end{array}$ & $\begin{array}{l}=\text { extremamente } \mathrm{m} \\
=\text { extremly tender, jui } \\
\text { the column, for compa }\end{array}$ & $\begin{array}{l}\text { amente suculenta e } \\
\text { ul]. } \\
\text { Charolais and Nellore }\end{array}$ \\
\hline
\end{tabular}

fato de os genótipos com mais de $50 \%$ de sangue zebuíno apresentarem problemas na maciez da carne, não se deveria ultrapassar $1 / 4$ de genótipo zebu nos cruzamentos, e, nas raças compostas com $3 / 8$ Bos indicus, os $5 / 8$ restantes devem ser compostos por uma raça européia com potencial genético para maciez da carne.

Outros trabalhos também têm comentado sobre as diferenças na maciez da carne a favor das raças taurinas em relação às zebuínas (Crouse et al., 1989; Wheeler et al., 1990; Whipple et al., 1990; Marshall et al., 1994; Perobelli et al., 1994; Flores, 1997; Restle et al., 1997; Restle et al., 1999).

Crouse et al. (1989) e Whipple et al. (1990) relataram que a diferença entre taurinos e zebuínos reside no fato de que a carne dos últimos apresenta, na sua estrutura, maior concentração de calpastatina, que atua como inibidor das enzimas proteolíticas do grupo calpaína, o que contribui para a menor maciez da carne dos zebuínos. Shackelford et al. (1994) citam correlação genética entre atividade da calpaína e resistência das fibras ao corte $(r=0,58)$.

Com relação à palatabilidade, observa-se que a carne dos novilhos Charolês foi de melhor palatabilidade que a carne dos novilhos Nelore $(\mathrm{P}<0,05)$. Segundo Wheeler et al. (1996), isso pode ser atribuído, em parte, às boas correlações fenotípicas que esta característica apresenta com as demais características sensoriais de carne. Pior palatabilidade na carne de animais zebuínos foi observada por Rocha et al. (1997), os quais citam que, à medida que aumentou o sangue Nelore no cruzamento com Hereford, a palatabilidade da carne decresceu.

Já ao estudarem vacas de descarte, Perobelli et al. (1994) mostram melhor palatabilidade da carne de vacas Nelore em relação às vacas Charolesas, relatando que isso foi devido ao maior grau de marmoreio das vacas Nelore. Já Wheeler et al. (1996) observaram que somente a resistência das fibras ao corte e a maciez da carne estiveram correlacionadas fenotipicamente com a palatabilidade da carne. Flores (1997), ao traçar equações de regressão para essa característica, verificou que a variação apresentou efeito quadrático em relação ao incremento de sangue Nelore no cruzamento com Hereford.

Ainda na Tabela 5, com relação à suculência da carne, observa-se que esta foi menor nos animais Nelore, em parte oriunda de maior perda de líquidos durante o preparo, conforme pode ser constatado na Tabela 6.

Verifica-se na Tabela 6 que os animais Nelore mostraram maiores perdas de líquido no descongelamento e à cocção do que os Charolês $(\mathrm{P}<0,05)$. A ocorrência de maiores perdas durante o preparo resulta em carne de menor suculência. Moletta \& Restle (1996b) verificaram perdas ao descongelamento e cocção de, respectivamente, 7,02 e $24,99 \%$, em novilhos Charolês, e 7,51 e 27,48\%, em novilhos Nelore. 
Tabela 6 - Valores para quebra ao descongelamento e à cocção da carne com relação à composição racial

Table 6 - Values for thawing and cooking losses of meat, according to the breed composition

\begin{tabular}{|c|c|c|}
\hline $\begin{array}{l}\text { Composição } \\
\text { racial } \\
\text { Breed } \\
\text { composition }\end{array}$ & $\begin{array}{c}\text { Quebra ao } \\
\text { descongelamento, \% } \\
\text { Thawing } \\
\text { loss, \% }\end{array}$ & $\begin{array}{l}\text { Quebra à } \\
\text { cocção, \% } \\
\text { Cooking } \\
\text { loss, \% }\end{array}$ \\
\hline Charolês (C) & $6,79^{\mathrm{a} 1}$ & $28,12 \mathrm{a}$ \\
\hline Nelore $(\mathrm{N})$ & $8,54^{\mathrm{b}}$ & $30,72 b$ \\
\hline Média puros & & \\
\hline Straightbreds mean & $7,66^{\mathrm{A}}$ & $29,42^{\mathrm{A}}$ \\
\hline $1 / 2 \mathrm{C} 1 / 2 \mathrm{~N}$ & $7,59^{\mathrm{c}}$ & $28,92^{\mathrm{c}}$ \\
\hline $1 / 2 \mathrm{~N} 1 / 2 \mathrm{C}$ & $7,75^{\mathrm{c}}$ & $29,88^{\mathrm{c}}$ \\
\hline Média $F_{1}$ & $7,67^{\mathrm{A}}$ & $29,40^{\mathrm{A}}$ \\
\hline $\begin{array}{l}F_{1} \text { mean } \\
\text { Heterose, } \% \\
\text { Heterosis, } \%\end{array}$ & $0,13\left(\mathrm{NS}^{2}\right)$ & $0,07(\mathrm{NS})$ \\
\hline
\end{tabular}

$\overline{1}$ a,b, na coluna, na comparação entre Charolês e Nelore, diferem pelo teste "t" $(P<0,05)[a, b$, in the column, for comparison between Charolais and Nellore, differ by " $t$ " test $(P<.05)]$.

2 indica heterose não-significativa $(P>0,05)$ [indicate not significant heterosis $(P>$.05)].

Utilizando animais abatidos aos quatorze meses, Flores (1997) e Restle et al. (1997) observaram que, em novilhos cruzados Nelore $x$ Hereford, o incremento de Nelore no genótipo aumentou a perda de líquidos durante o descongelamento, fazendo com que a suculência da carne decrescesse. Trabalhando com animais de quatorze meses $3 / 4 \mathrm{C} 1 / 4 \mathrm{~N}$ ou $3 / 4$ Hereford 1/4 N, Rocha et al. (1997) verificaram que os cruza Charolês apresentaram carne de menor quebra ao cozimento, mas não verificaram diferenças na suculência da carne dos animais.

\section{Conclusões}

Novilhos Charolês abatidos aos dois anos apresentaram mais músculo na carcaça, carne de textura mais fina, mais saborosa, mais suculenta e mais macia que os Nelore.

Novilhos Nelore apresentaram carcaça com maior percentual de osso e de gordura que os Charolês, assim como a carne apresenta maior perda ao descongelamento e cocção.

Novilhos 1/2 C 1/2 N abatidos aos dois anos de idade apresentaram menor percentual de músculo na carcaça, porém maior porcentagem de gordura e carne com maior marmoreio que novilhos $1 / 2 \mathrm{~N} 1 / 2 \mathrm{C}$.

$\mathrm{O}$ cruzamento entre as raças Charolês e Nelore produziu animais $\mathrm{F}_{1}$ com valores positivos e significativos de heterose para características importantes aos frigoríficos e ao consumidor, como percentual de gordura na carcaça, relação músculo/osso, músculo + gordura/osso e marmoreio.

\section{Agradecimento}

Ao professor da UFRGS, Flávio Miguel Schenkel, em função do auxílio prestado nas análises estatísticas.

\section{Literatura Citada}

ALENCAR, M.M.; TREMATORE, R.L.; BARBOSA, P.F. et al. Estudo da influência da linhagem citoplasmática sobre pesos em bovinos da raça Canchim. In: REUNIÃO ANUAL DA SOCIEDADE BRASILEIRA DE ZOOTECNIA, 34., 1997, Juiz de Fora. Anais... Juiz de Fora: Sociedade Brasileira de Zootecnia, 1997. p.230-232.

ARTHUR, P.F.; MAKARECHIAN, M.; PRICE, M.A. et al. Heterosis, maternal and direct effects in double-muscled and normal cattle: II. Carcass traits of young bulls. Journal of Animal Science, v.67, n.4, p.911-919, 1989.

BARBER, K.A.; WILSON, L.L.; ZIEGLER, J.H. et al. Charolais and Angus steers slaughtered at equal percentages of mature cow weight. I. Effects of slaughter weight and energy density on carcass traits. Journal of Animal Science, v.52, n.2, p.218-231, 1981.

CROUSE, J.D.; CUNDIFF, L.V.; KOCH, R.M. et al. Comparisons of Bos indicus and Bos taurus inheritance for carcass beef characteristics and meat palatability. Journal of Animal Science, v.67, n.10, p.2661-2668, 1989.

DeROUEN, S.M.; FRANKE, D.E.; BIDNER, T.D. et al. Direct and maternal genetic effects for carcass traits in beef cattle. Journal of Animal Science, v.70, n.12, p.3677-3685, 1992a.

DeROUEN, S.M.; FRANKE, D.E.; BIDNER, T.D. et al. Twothree-, and four-breed rotational crossbreeding of beef cattle: carcass traits. Journal of Animal Science, v.70, n.12, p.3665-3676, 1992 b.

FEIJÓ, G.L.D.; EUCLIDES FILHO, K.; FIGUEIREDO, G.R. et al. Avaliação de carcaças de Nelore e $F_{1}$ 's europeu-Nelore a um grau de acabamento constante. In: REUNIÃO ANUAL SOCIEDADE BRASILEIRA DE ZOOTECNIA, 34., 1997, Juiz de Fora. Anais... Juiz de Fora: Sociedade Brasileira de Zootecnia, 1997. p.133-135.

FLORES, J.L.C. Desempenho em confinamento e características de carcaça e da carne de bovinos de diferentes grupos genéticos abatidos aos quatorze meses. Santa Maria, RS: Universidade Federal de Santa Maria, 1997. 109p. Dissertação (Mestrado em Zootecnia) - Universidade Federal de Santa Maria, 1997.

FRANKE, D.E. Postweaning performance and carcass merit of F1 steers sired by Brahman and alternative subtropically adapted breeds. Journal of Animal Science, v.75, n.9, p.2604-2608, 1997.

GREGORY, K.E.; CUNDIFF, L.V.; KOCH, R.M. et al. Breed effects, retained heterosis, and estimates of genetic and phenotypic parameters for carcass and meat traits of beef cattle. Journal of Animal Science, v.72, n.5, p.1174-1183, 1994.

GREGORY, K.E.; DEARBORN, D.D.; CUNDIFF, L.V. et al. Maternal heterosis and grandmaternal effects in beef cattle: postweaning growth and carcass traits. Journal of Animal Science, v.65, n.5, p.1180-1194, 1987. 
HANKINS, O.G.; HOWE, P.E. Estimation of the composition of beef carcasses and cuts. Washington, DC: United States Department of Agriculture, 1946. (Technical Bulletin, 926).

JOHNSTON, D.J.; THOMPSON, J.M.; HAMMOND, K. Additive and nonadditive differences in postweaning growth and carcass characteristics of Devon, Hereford, and reciprocalcross steers. Journal of Animal Science, v.70, n.9, p.2688-2694, 1992.

KOGER, M. Effective crossbreeding systems utilizing zebu cattle. Journal of Animal Science, v.50, n.6, p.1213-1220, 1980.

LUCHIARI FILHO, A.; LEME, P.R.; RAZOOK, A.G. et al. Características de carcaça e rendimento de porção comestível de machos Nelore comparados a cruzados $\left(\mathrm{F}_{1}\right)$ obtidos do acasalamento de touros das raças Canchim, Santa Gertrudis, Caracu, Holandês e Suiço com fêmeas Nelore. II. Animais castrados terminados a pasto. Boletim da Indústria Animal, v.46, n.1, p.27-35, 1989.

MARSHALL, D.M. Breed differences and genetic parameters for body composition traits in beef cattle. Journal Animal Science, v,72, n.10, p.2745-2755, 1994.

MARSHALL, T.T.; HARGROVE, D.D.; OLSON, T.A. Heterosis and additive breed effects on feedlot and carcass traits from crossing Angus and Brown Swiss. Journal of Animal Science, v.64, n.5, p.1332-1339, 1987.

MARSHALL, D.M.; MONFORE, M.D.; COSTELLO, W.J. et al. Performance of Hereford and two-breed rotational crosses of Hereford with Angus and Simmental cattle: II. Carcass traits of steers. Journal of Animal Science, v.68, n.12, p.4060-4068, 1990.

MOLETTA, J.L.; RESTLE, J. Características de carcaça de novilhos de diferentes grupos genéticos terminados em confinamento. Revista da Sociedade Brasileira de Zootecnia, v.26, n.5, p.876-888, 1996 a.

MOLETTA, J.L.; RESTLE, J. Influência do grupo genético sobre características qualitativas da carne de novilhos. Revista da Sociedade Brasileira de Zootecnia, v.26, n.5, p.866-875, 1996b.

MULLER, L. Normas para avaliação de carcaças e concurso de carcaça de novilhos. 2.ed. Santa Maria: Universidade Federal de Santa Maria, 1987. 31p.

O'CONNOR, S.F.; TATUM, J.D.; WULF, D.M. et al. Genetic effects on beef tendernes in Bos indicus composite and Bos taurus cattle. Journal of Animal Science, v.75, n.7, p.18221830, 1997.

OLSON,L.W.; CUNDIFF,L.V.; GREGORY,K.E. Maternal heterosis effects on postweaning growth and carcass traits in beef cattle. Journal of Animal Science, v.46, n.6, p.1552-1562, 1978.

PASCHAL, J.C.; SANDERS, J.O.; KERR, J.L. et al. Postweaning and feedlot growth and carcass characteristics of Angus-, Gray Brahman-, Gir-, Indu-Brazil-, Nellore-, and Red Brahmansired $F_{1}$ calves. Journal of Animal Science, v.73, n.2, p.373-380, 1995.

PEROBELLI, Z.V.; MULLER, L.; RESTLE, J. Estudo da qualidade das carcaças e da carne de vacas de descarte de dois grupos genéticos. Ciência Rural, v.24, n.3,p.613-616. 1994.

PEROBELLI, Z.V., RESTLE, J., MULLER, L. Estudo das carcaças de vacas de descarte das raças Charolês e Nelore. Pesquisa Agropecuária Brasileira, v.30, n.3. p.409-412, 1995.

PEROTTO, D., CUBAS, A.C., MOLETTA, J.L. et al. Pesos ao nascimento e à desmama e ganho de peso do nascimento à desmama de bovinos Charolês, Caracu e cruzamentos recíprocos. Revista Brasileira de Zootecnia, v.27, n.4, p.730-737, 1998.

R. Bras. Zootec., v.31, n.1, p.376-386, 2002 (suplemento)
PEROTTO, D.; MOLETTA, J.L.; CUBAS, A.C. Características quantitativas da carcaça de bovinos Charolês, Caracu e cruzamentos recíprocos terminados em confinamento. Revista Brasileira de Zootecnia, v.29, n.1, p.117-124, 2000.

RESTLE, J.; FELTEN, H.G.; VAZ, F.N. Efeito de raça e heterose para características quantitativas da carcaça de novilhos de 24 meses terminados em confinamento. In: REUNIÓN LATINOAMERICANA DE PRODUCCIÓN ANIMAL, 14., 1995, Mar del Plata. Memorias... Balcarce: Associación Latino American de Producción Animal, 1995a. p.857-859.

RESTLE, J.; FELTEN, H.G.; VAZ, F.N. Efeito de raça e heterose para desempenho em confinamento de novilhos de corte. In: REUNIÓN LATINOAMERICANA DE PRODUCCIÓN ANIMAL, 14., 1995, Mar del Plata. Memorias... Balcarce: Associación Latino American de Producción Animal, 1995b. p. 852-854.

RESTLE, J.; FELTEN, H.G.; VAZ, F.N. et al. Efeito de raça e heterose para qualidade da carcaça e da carne de novilhos terminados em confinamento. In: REUNIÓN LATINOAMERICANA DE PRODUCCIÓN ANIMAL, 14., 1995, Mar del Plata. Memorias... Balcarce: Associación Latino American de Producción Animal, 1995c. p.854-856.

RESTLE, J.; ROCHA, J.B.T.; FLORES, J.L.C. et al. Qualidade da carne de animais hereford e suas cruzas com Nelore, abatidos aos quatorze meses. In: REUNIÃO ANUAL DA SOCIEDADE BRASILEIRA DE ZOOTECNIA, 34., 1997, Juiz de Fora. Anais... Juiz de Fora: Sociedade Brasileira de Zootecnia, 1997. p.196-198.

RESTLE, J.; VAZ, F.N. Confinamento de bovinos puros e cruzados. In: LOBATO, J.F.P.; BARCELLOS, J.O.J.; KESSLER, A.M. (Eds.) Produção de bovinos de corte. Porto Alegre: EDIPUCRS, 1999. p.141-168.

RESTLE, J.; VAZ, F.N.; QUADROS, A.R.B. et al. Características de carcaça e da carne de novilhos de diferentes genótipos Hereford x Nelore. Revista Brasileira de Zootecnia, v.28, n.6, p.1245-1251, 1999.

ROCHA, J.B.T.; PEROTTONI, J.; RESTLE, J. et al. Qualidade da carne de animais inteiros de dois grupos genéticos, abatidos aos quatorze meses de idade. In: REUNIÃO ANUAL DA SOCIEDADE BRASILEIRA DE ZOOTECNIA, 34., 1997, Juiz de Fora. Anais... Juiz de Fora: Sociedade Brasileira de Zootecnia, 1997. p.199-201.

ROHRER, G.A.; TAYLOR, J.F.; SANDERS, J.O. et al. Evaluation of line and breed of cytoplasm effects on performance of purebred Brangus cattle. Journal of Animal Science, v.72, n.11, p.2798-2803, 1994.

ROSO, V.M. Heteroses materna e individual sobre o ganho e peso do nascimento ao desmame em bovinos Angus x Nelore. In: REUNIÃO ANUAL DA SOCIEDADE BRASILEIRA DE ZOOTECNIA, 34., 1997, Juiz de Fora. Anais... Juiz de Fora: Sociedade Brasileira de Zootecnia, 1997. p.139-141.

SAS INSTITUTE. Language reference. Version 6, Cary: 1990. $1042 \mathrm{p}$.

SHACKELFORD, S.D.; KOOHMARAIE, M.; CUNDIFF, L.V. et al. Heritabilities and phenotypic and genetic correlations for bovine postrigor calpastatin activity, intramuscular fat content, Warner-Bratzler shear force, retail product yield, and growth rate. Journal of Animal Science, v.72, n.3, p.857-863, 1994.

SLANGER, W.D.; MARCHELLO, M.J.; DANIELSON, R.B. et al. Muscle tenderness, other carcass traits and the effect of crossbreeding on these traits in beef cattle. Journal of Animal Science, v.61, n.6, p.1402-1410, 1985. 
URICK, J.J.; PAHNISH, O.F.; KNAPP, B.W. Comparison of two- and three-way rotational crossing, beef $x$ beef and beef $\mathrm{x}$ brown swiss composite breed production: postweaning growth and carcass traits. Journal of Animal Science, v.67, n.10, p.2603-2618, 1989.

WHEELER, T.L.; CUNDIFF, L.V.; KOCH, R.M. Characterization of biological types of cattle (Cycle IV): carcass traits and longissimus palatability. Journal of Animal Science, v.74, n.5, p.1023-1035, 1996.

WHEELER, T.L.; SAVELL, J.W.; CROSS, H.R. et al. Mechanisms associated with the variation in tenderness of meat from Brahman and Hereford cattle. Journal of Animal Science, v.68, n.12, p.4206-4220, 1990.
WHEELER, T.L.; CUNDIFF, L.V.; KOCH, R.M. et al. Characterization of different biological types of steers (Cycle IV): wholesale, subprimal, and retail product yields. Journal of Animal Science, v.75, n.9, p.2389-2403, 1997.

WHIPPLE, G.; KOOHMARAIE, M.; DIKEMAN, M.E. et al. Evaluation of attributes that affect longissimus muscle tenderness in Bos taurus and Bos indicus cattle. Journal of Animal Science, v.68, n.9, p.2716-2728, 1990.

Recebido em: 23/05/00

Aceito em: 02/08/01 